\title{
Pengaruh Styrofoam sebagai Bahan Tambah dalam Campuran Laston Lapis Antara
}

\author{
Richard Marcelenus Pasapan*1, Nur Ali*2, Rais Rachman*3 \\ *1 Mahasiswa program studi teknik sipil di Universitas Kristen Paulus Indonesia Makassar, \\ Indonesia richardpasapan39@gmail.com \\ *2,3 Dosen program studi teknik sipil Universitas Kristen Paulus Indonesia, Makassar, Indonesia \\ nurali.mt@gmail.com dan rais.rachman@gmail.com
}

Corresponding Author: rais.rachman@gmail.com

\begin{abstract}
ABSTRAK
Penelitian ini bertujuan untuk pengujian Penggunaan Styrofoam sebagai bahan tambah dalam campuran Laston Lapis Antara. Metodologi yang digunakan adalah perancangan desain campuran Laston Lapis Antara dan pengujian perendaman Marshall untuk karakteristik campuran. Hasil penelitian melalui uji perendaman Marshall konvensional diperoleh campuran Laston Lapis Antara dengan kadar Styrofoam sebagai bahan tambah yaitu 0\%, 1\%, 2\%, 3\%, 4\% dengan kadar aspal 5,0 \% memenuhi persyaratan standar Bina Marga 2018. Hasil pengujian karakteristik Marshall Konvensional campuran Laston Lapis Antara dengan bahan tambah Styrofoam yaitu jika kadar Styrofoam bertambah, maka nilai nilai VIM, Flow dan VMA yang mengalami penurunan pada setiap kadar Styrofoamnya, sedangkan untuk nilai Stabilitas, dan VFB yang mengalami peningkatan. Pengaruh penambahan Styrofoam dapat meningkatkan kinerja campuran Laston Lapis Antara, dimana nilai stabilitas meningkat dan kelelehannya menurun.
\end{abstract}

Kata kunci: Karakteristik, Styrofoam, AC - BC , Pengujian Marshall

\section{ABSTRACT}

This research is intended to test the use of Styrofoam as an additive in the mixture of Laston Lapis Antara.The methodology used is the design of the Intermediate Laston mixture design and the Marshall immersion test for the characteristics of the mixture. The results of the research through the conventional Marshall test, obtained a mixture of Laston Lapis Antara with Styrofoam content, namely $0 \%, 1 \%, 2 \%, 3 \%, 4 \%$ with an asphalt content of 5.0\% meeting the requirements of the 2018 Highways standard. The results of testing the characteristics of the Conventional Marshall Mix of Laston Layer Between with added Styrofoam ingredients are that if the Styrofoam content increases, the VIM, Flow and VMA values decrease at each Styrofoam level, while the Stability and VFB values increase. The effect of adding Styrofoam can improve the performance of the Laston Lapis Antara mixture, where the stability value increases and the meltdown decreases.

Keywords: Characteristics, Styrofoam, AC - BC, Marshall Testing.

\section{PENDAHULUAN}

Lapis Aspal Beton (LASTON) adalah lapisan perkerasaan jalan yang tersusun atas campuran agregat dan aspal yang dihampar dan dipampatkan pada kondisi panas dengan suhu tertentu [1]. Karakterikstik yang dimiliki oleh LASTON itu sendiri adalah Stabilitas (Kemampuan), Durabilitas (Keawetan), Fleksibilitas (Kelenturan), Tahan Geser, dan Ketahanan Terhadap Kelelehan [2]. LASTON terdiri atas 3 macam lapisan 
salah satunya Laston Lapis Antara. Laston lapisan antara (AC-BC) adalah merupakan lapisan yang tidak berhubungan langsung dengan cuaca, tetapi harus memiliki ketebalan dan kekakuan yang cukup untuk mengurangi tegangan atau regangan yang diakibatkan oleh beban lalu lintas lalu diteruskan ke bagian lapisan base dan sub grade (tanah dasar) [3]. Karakteristik yang terpenting dalam campuran ini adalah stabilitas.

Saat ini kebutuhan akan jalan raya semakin meningkat, sehingga mengingat banyaknya kerusakan jalan yang disebabkan oleh tonase kendaraan atau beban kendaraan yang berlebihan (over load) dan masuknya air pada campuran beraspal maka diperlukan kualitas perkerasan yang baik. Kerusakan pada jalan diakibatkan oleh kelembapan atau masuknya air pada campuran beraspal menyebabkan terjadinya stripping yaitu terjadinya pengelupasan pada lapisan aspal dari butir agregat diakibatkan hilangnya daya lekat antara aspal dan permukaan agregat [4] [5]. Oleh sebab itu, penggunaan bahan tambah (additive) dan filler menjadi salah satu alternatif yang diharapkan dapat meningkatkan kualitas beton aspal [6].

Seiring dengan perkembangan teknologi material khususnya pekerjaan perkerasan jalan, muncul ide untuk memanfaatkan bahan-bahan yang tak terpakai atau limbah sebagai bahan penyusun dan bahan tambah [7]. Salah satunya memanfaatkan Styrofoam sebagai campuran aspal. Saat ini sudah banyak digunakan berbagai macam bahan tambah untuk meningkatkan mutu campuran aspal, antara lain dengan menambahkan polimer. Salah satu polimer yang digunakan adalah Styrofoam. Styrofoam telah diteliti sebagai bahan aditif pada aspal, karena sifatnya yang termoplastik padat pada suhu ruangan dan akan mencair pada suhu yang lebih tinggi, maka dapat digunakan sebagai bahan pengikat baru untuk perkerasan konstruksi jalan. Sifat yang di miliki Styrofoam sama dengan sifat aspal sehingga bisa menjadi inovasi mejadi bahan tambah (additive) dalam campuran lapisan aspal beton. Selain penggunaan Styrofoam sebagai bahan tambah (additive) untuk perkuatan perkerasan jalan aspal beton dapat mengurangi jumlah limbah di Indonesia, mengingat jumlah limbah Styrofoam selalu meningkat dari tahun ke tahun. Penelitian tentang penggunaan Styrofoam untuk lapisan permukaan yang pernah dilakukan diantaranya "Pemanfaatan Limbah Styrofoam Sebagai Bahan Tambah Campuran AC-BC Yang Menggunakan Sungai Bittuang" [8]. "Pengaruh Styrofoam Sebagai Bahan Tambah Pada Campuran Laston Lapis Aus" [9]. "Pemanfaatan Limbah Styrofoam Sebagai Bahan Additive pada Asphalt Concrete-Wearing Course (AC-WC) terhadap Karakteristik Marshall" [10]. "Pengaruh Substitusi Styrofoam pada Campuran Asphalt Concrete - Binder Course (AC-BC) dengan Pengujian Marshall" [11].

Kemajuan teknologi tentang bahan material konstruksi dari tahun ke tahun semakin meningkat terutama dalam penggunaan material yang berasal dari alam yang digunakan sebagai bahan utama dalam campuran perkerasan jalan [12]. Sungai Malili adalah sungai yang terletak di Kecamatan Malili Kabupaten Luwu Timur yang kaya akan sumber alamnya berupa material batuan yang dapat digunakan sebagai bahan material konstruksi. Hasil Penelitian tentang pemanfaatan Batu Sungai Malili Kabupaten Luwu Timur sebagai agregat dalam campuran Laston Lapis Antara menunjukkan hasil dimana Batu Sungai Malili memenuhi spesifikasi yang ditetapkan oleh Direktorat Jenderal Bina Marga 2018 sebagai material yang digunakan untuk perkerasan jalan [13].

\section{METODOLOGI}

\section{Lokasi Pengambilan Agregat}

Agregat yang akan digunakan berasal dari Sungai Malili yang terletak di Kabupaten Luwu Timur. Tujuan pengambilan material untuk mendapatkan material yang akan diuji di laboratorium Jalan dan Aspal UKI Paulus Makassar untuk dilakukan pengujian selanjutnya. 


\section{Persiapan Material}

Dimana agregat berupa batuan dari Sungai Malili sebelum pemeriksaan di laboratorium dilakukan pemecah batu dengan ukuran-ukuran yang dibutuhkan sesuai spesifikasi campuran Lason Lapis Antara.

\section{Karakteristik Agregat, Aspal, dan Filler.}

Pemeriksaan karakteristik bahan berdasarkan penelitian yang telah dilakukan pada pemeriksaan karakteristik agregat kasar, halus, aspal, dan filler oleh Ardiyanto Tangdiongan (2020) sebelumnya dari Batu Sungai Malili Kabupaten Luwu Timur.

\section{Komposisi Campuran.}

Berdasarkan perhitungan kebutuhan bahan campuran dan penambahan Styrofoam diperoleh komposisi campuran Laston Lapis Antara sebagai berikut :

Tabel 1. Komposisi Campuran

\begin{tabular}{cccccc}
\hline \multirow{2}{*}{ Material } & \multicolumn{5}{c}{ Kadar Styrofoam } \\
\cline { 2 - 6 } & $\mathbf{0 \%}$ & $\mathbf{1 \%}$ & $\mathbf{2 \%}$ & $\mathbf{3 \%}$ & $\mathbf{4 \%}$ \\
\hline Agregat Kasar (gr) & 518,2 & 518,2 & 518,2 & 518,2 & 518,2 \\
\hline Agregat Halus (gr) & 555,3 & 555,3 & 555,3 & 555,3 & 555,3 \\
\hline Filler (gr) & 66,55 & 66,55 & 66,55 & 66,55 & 66,55 \\
\hline Styrofoam (gr) & 0,00 & 0,60 & 1,20 & 1,80 & 2,40 \\
\hline Aspal (gr) & 60,0 & 60,0 & 60,0 & 60,0 & 60,0 \\
\hline Total Berat (gr) & 1200 & 1200,6 & 1201,2 & 1201,8 & 1202,4 \\
\hline
\end{tabular}

\section{Pembuatan Benda Uji Untuk Campuran Laston Lapis Aus}

Dalam pelaksanaannya pada penelitian benda uji yang digunakan ada 18 sampel yang terdiri dari pengujian Marshall Konvensional 15 buah.

Tabel 2. Rancangan Jumlah Benda Uji Campuran

\begin{tabular}{|c|c|c|}
\hline $\begin{array}{c}\text { Kadar Aspal } \\
(\%)\end{array}$ & $\begin{array}{c}\text { Kadar } \\
\text { Styrofoam(\%) }\end{array}$ & $\begin{array}{c}\text { Marshall } \\
\text { Konvensional (bh) }\end{array}$ \\
\hline \multirow{5}{*}{5,00} & 0 & 3 \\
\hline & 1 & 3 \\
\hline & 2 & 3 \\
\hline & 3 & 3 \\
\hline & 4 & 3 \\
\hline \multicolumn{2}{|c|}{ Jumlah } & 15 \\
\hline
\end{tabular}

\section{HASIL DAN PEMBAHASAN}

\section{Hasil Perhitungan Bulk Spesific Gravity dan Effective Spesific Gravity}

Benda uji dibuat dengan kadar aspal untuk campuran Laston Lapis Antara yaitu 5,0\% dengan bahan tambah Styrofoam dengan kadar penambahan 0\%, 1\%, 2\%, 3\%, dan 4\%. Hasil perhitungan Bulk Spesific Gravity dan Effective Spesific Gravity dapat dilihat pada Tabel 3 di bawah ini: 
Tabel 3. Bulk Spesific Gravity dan Effective Spesific Geavity

\begin{tabular}{cccccc}
\hline \multirow{2}{*}{ Berat jenis } & \multicolumn{5}{c}{ Kadar Styrofoam (\%) } \\
\cline { 2 - 6 } & $\mathbf{0}$ & $\mathbf{1 , 0}$ & $\mathbf{2 , 0}$ & $\mathbf{3 , 0}$ & $\mathbf{4 , 0}$ \\
\hline $\begin{array}{c}\text { Bulk Spesific Gravity } \\
\text { Agregat }\end{array}$ & 2,76 & 2,75 & 2,75 & 2,75 & 2,75 \\
\hline $\begin{array}{c}\text { Effective Spesific } \\
\text { Gravity Agregat }\end{array}$ & 2,77 & 2,77 & 2,77 & 2,77 & 2,77 \\
\hline
\end{tabular}

\section{Hasil Pengujian Marshall Konvensional}

Dari hasil pengujian Marshall karakteristik campuran seperti terlihat pada Tabel 4.

Tabel 4. Hasil Pengujian Campuran

\begin{tabular}{|c|c|c|c|c|c|c|}
\hline $\begin{array}{c}\text { Kadar aspal } \\
(\%)\end{array}$ & $\begin{array}{c}\text { Kadar } \\
\text { Styrofoam }(\%)\end{array}$ & VIM & Stabilitas & $V F B$ & Flow & $V M A$ \\
\hline 5,0 & 0 & 4,91 & 1199,60 & 69,93 & 3,00 & 16,34 \\
\hline 5,0 & 1 & 4,78 & 1859,38 & 70,55 & 2,70 & 16,21 \\
\hline 5,0 & 2 & 4,55 & 2267,25 & 71,60 & 2,43 & 16,02 \\
\hline 5,0 & 3 & 4,39 & 2391,21 & 72,31 & 2,33 & 15,86 \\
\hline \multirow[t]{2}{*}{5,0} & 4 & 4,12 & 2451,19 & 73,31 & 2,13 & 15,63 \\
\hline & Persyaratan & $3-5(\%)$ & Min $800(\mathrm{~kg})$ & Min $65(\%)$ & $2-4(\mathrm{~mm})$ & Min $14(\%)$ \\
\hline
\end{tabular}

\section{a. Analisa Terhadap Stabilitas}

Hasil pengujian terhadap stabilitas dapat dilihat pada Tabel 5 dan Gambar 1 di bawah ini .

Tabel 5. Nilai hasil analisis Stabilitas

\begin{tabular}{cccccc}
\hline \multirow{2}{*}{$\begin{array}{c}\text { Kadar Styrofoam } \\
(\%)\end{array}$} & 0,00 & 1,00 & 2,00 & 3,00 & 4,00 \\
& & & & & \\
\hline \multirow{2}{*}{ Stabilitas } & 1199,60 & 1859,38 & 2267,25 & 2399,20 & 2447,19 \\
\cline { 2 - 6 } & 1211,60 & 1847,39 & 2255,25 & 2387,21 & 2459,18 \\
\cline { 2 - 6 } & 1187,61 & 1871,38 & 2279,24 & 2387,21 & 2447,19 \\
\hline Rata-Rata & 1199,60 & 1859,38 & 2267,25 & 2391,21 & 2451,19 \\
\hline
\end{tabular}




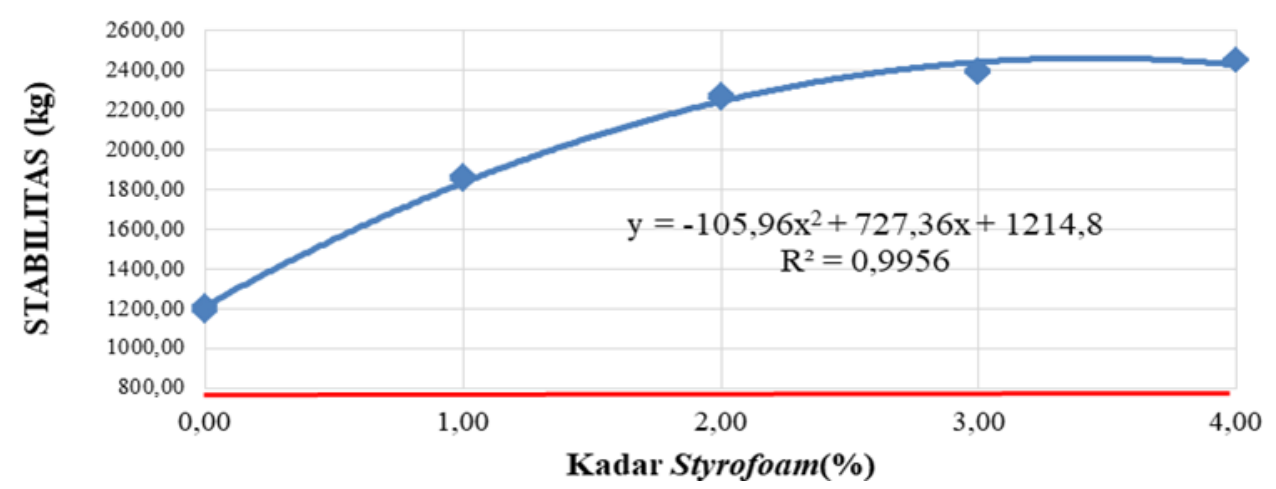

Gambar 1. Hubungan Kadar Styrofoam dengan Stabilitas

Dengan Menggunakan kadar Styrofoam 0\%, 1\%, 2\%, 3\%, dan 4\% didapatkan nilai stabilitas untuk kadar Styrofoam 0\% sebesar 1199,60 Kg, untuk kadar Styrofoam 1\% terjadi kenaikan sebesar 1859,38 Kg, untuk kadar Styrofoam 2\% terjadi kenaikan sebesar 2267,25 Kg, untuk kadar Styrofoam 3\% terjadi kenaikan sebesar 2391,21 Kg, dan untuk kadar Styrofoam 4\% terjadi kenaikan sebesar 2451,19 Kg. Semua nilai stabilitas dengan kadar Stytrofoam 0\%, 1\%, 2\%, 3\%, dan 4\% memenuhi Spesifikasi Umum Bina Marga Tahun 2018. Dimana grafik nilai stabilitas yang diperoleh berbentuk parabola. Nilai stabilitas tertinggi diperoleh yaitu campuran berkadar Styrofoam 4\% yaitu 2451,19 Kg. Berdasarkan Gambar 5 dapat disimpulkan bahwa penggunaan kadar bahan tambah Styrofoam yang sedikit dalam campuran Laston Lapis Antara akan menghasilkan selimut aspal yang tipis dipermukaan material agregat yang menyebabkan ikatan antara agregat (Interlocking) menjadi lemah sehingga nilai stabilitas pada campuran kecil, jika kadar Styrofoam bertambah maka ikatan antara agregat akan menjadi lebih kuat/stabilitas campuran besar.

\section{b. Analisa Terhadap VIM (Void in Mix)}

Hasil pengujian analisis terhadap VIM dapat dilihat pada Tabel 6 dan Gambar 2.

Tabel 6. Nilai hasil analisis VIM

\begin{tabular}{cccccc}
\hline \multirow{2}{*}{$\begin{array}{c}\text { Kadar } \\
\text { Styrofoam }(\%)\end{array}$} & 0,00 & 1,00 & 2,00 & 3,00 & 4,00 \\
\hline \multirow{2}{*}{ VIM } & 4,96 & 4,79 & 4,51 & 4,35 & 4,08 \\
\cline { 2 - 6 } & 4,85 & 4,64 & 4,51 & 4,39 & 4,16 \\
\hline Rata-Rata & 4,93 & 4,89 & 4,63 & 4,43 & 4,11 \\
\hline
\end{tabular}

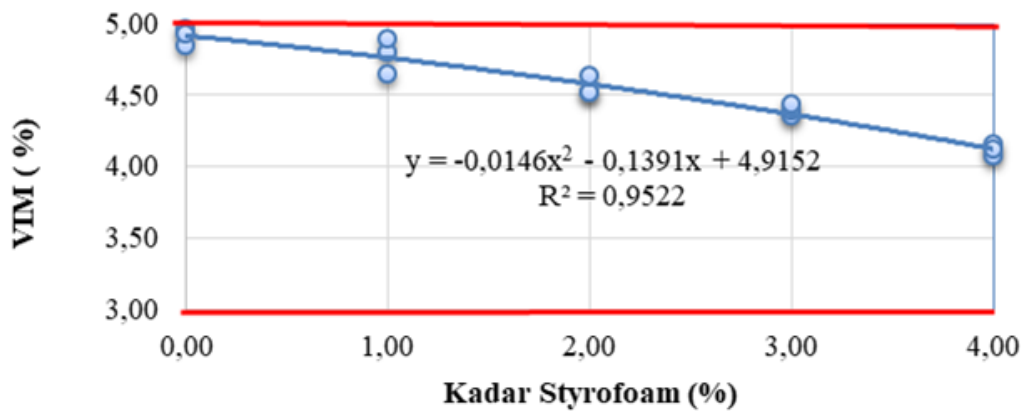




\section{Gambar 2. Hubungan Kadar Styrofoam dengan VIM}

Dengan menggunakan kadar Styrofoam 0\%, 1\%, 2\%, 3\%, dan 4\% diperoleh nilai VIM untuk kadar Styrofoam $0 \%$ sebesar 4,91\%, untuk kadar Styrofoam $1 \%$ terjadi penurunan $4,78 \%$, untuk kadar Styrofoam $2 \%$ terjadi penurunan 4,55\%, untuk kadar Styrofoam 3\% terjadi penurunan 4,39\%, dan untuk kadar Styrofoam 4\% terjadi penurunan 4,12\%. Semua nilai VIM dengan kadar Stytrofoam 0\%, 1\%, 2\%, 3\%, dan 4\% memenuhi Spesifikasi Umum Bina Marga Tahun 2018. Berdasarkan Gambar 2 dapat disimpulkan bahwa semakin tinggi kadar Styrofoam yang digunakan maka nilai VIM yang didaptkan akan semakin kecil begitu pula juga sebaliknya, apabila kadar Styrofoam yang digunakan kecil maka nilai VIM yang didapatkan akan semakin besar, ini disebabkan karena bahan tambah Styrofoam berfungsi sebagai pengikat dan pengisi rongga di dalam campuran beraspal. Penggunaan Styrofoam yang banyak akan dapat merubah bentuk plastis pada campuran dan merubah kekuatan campuran.

\section{c. Analisa Terhadap Flow}

Hasil pengujian analisis terhadap Flow dapat dilihat sebagai berikut:

Tabel 7. Nilai hasil analisis Flow

\begin{tabular}{cccccc}
\hline \multirow{2}{*}{$\begin{array}{c}\text { Kadar } \\
\text { Styrofoam }(\%)\end{array}$} & 0,00 & 1,00 & 2,00 & 3,00 & 4,00 \\
\hline \multirow{2}{*}{ Flow } & 2,90 & 2,70 & 2,40 & 2,30 & 2,10 \\
\cline { 2 - 6 } & 3,00 & 2,60 & 2,50 & 2,30 & 2,20 \\
\hline Rata-Rata & 3,10 & 2,80 & 2,40 & 2,40 & 2,10 \\
\hline
\end{tabular}

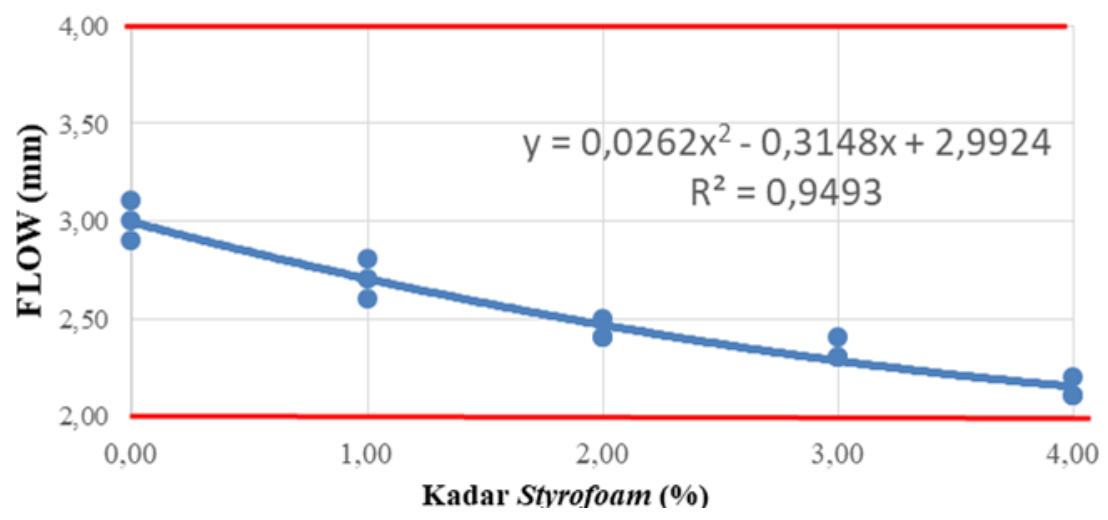

Gambar 3 Hubungan Kadar Styrofoam dengan Flow

Dengan menggunakan kadar Styrofoam 0\%, 1\%, 2\%, 3\%, dan 4\% diperoleh nilai Flow pada kadar Styrofoam 0\% sebesar 3,00 mm, untuk kadar Styrofoam 1\% terjadii penurunan sebesar 2,7 mm, untuk kadar Styrofoam 2\% terjadii penurunan sebesar 2,43 mm, untuk kadar Styrofoam 3\% terjadii penurunan sebesar 2,33 mm, dan untuk kadar Styrofoam 4\% terjadii penurunan sebesar 2,13 mm. Semua nilai Flow dengan kadar Stytrofoam 0\%, 1\%, 2\%, 3\%, dan 4\% memenuhi Spesifikasi Umum Bina Marga Tahun 2018. Berdasarkan Gambar 3 disimpulkan bahwa jika penggunaan bahan tambah Styrofoam pada campuran beraspal kecil maka terjadi ikatan antar agregat akan berkurang yang menyebabkan kelelehan menjadi besar, 
kemudian jika penggunaan bahan tambah Styrofoam bertambah maka selimut aspal menebal yang menyebabkan kekuatan campuran berkurang tetapi kelelehannya menjadi besar, yang artinya nilai stabilitas akan berbanding terbalik dengan nilai Flow.

\section{d. Analisa Terhadap VMA (Void in Mineral Aggregate)}

Hasil pengujian analisis terhadap VAM dapat dilihat pada Tabel 8 dan Gambar 4 di bawah ini :

Tabel 8. NilaiI hasil analisis VMA

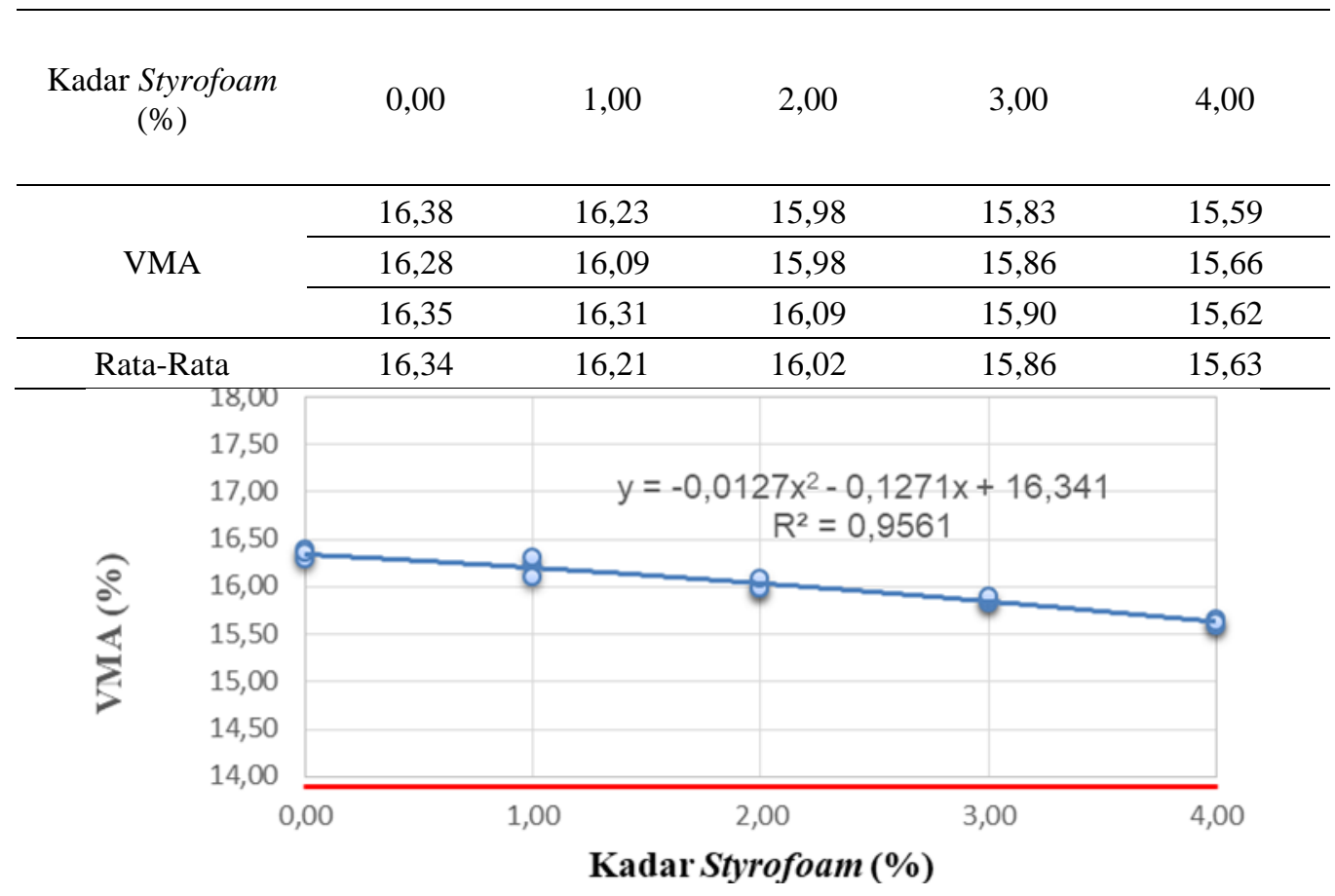

Gambar 4. Hubungan Kadar Styrofoam dengan VMA

Dengan menggunakan kadar Styrofoam 0\%, 1\%, 2\%, 3\%, dan 4\% diperoleh nilai VMA untuk kadar Styrofoam 0\% sebesar 16,34\%, untuk kadar Styrofoam 1\% terjadi penurunan sebesar 16,21\%, untuk kadar Styrofoam 2\% terjadi penurunan sebesar 16,02\%, untuk kadar Styrofoam 3\% terjadi penurunan sebesar $15,86 \%$, dan untuk kadar Styrofoam 4\% terjadi penurunan sebesar 15,63\%. Semua nilai VMA dengan kadar Stytrofoam 0\%, 1\%, 2\%, 3\%, dan 4\% memenuhi Spesifikasi Umum Bina Marga Tahun 2018. Berdasarkan Gambar 4 dapat disimpulkan bahwa semakin besar kadar Styrofoam yang digunakan maka nilai VMA semakin kecil begitu juga sebaliknya apabila kadar Styrofoam yang digunakan semakin kecil maka nilai VMA semakin besar, hal ini disebabkan penggunaan kadar variasi Styrofoam yang banyak dimana pada saat pencampuran, Styrofoam akan mengisi rongga diantara agregat dan mengisi rongga dalam agregat.

\section{e. Analisa Terhadap VFB (Void Filled With Bitumen)}

Hasil pengujian analisis terhadap VFB dapat dilihat pada Tabel 9 dan Gambar 5 sebagai berikut

Tabel 9. Nilai hasil analisis VFB

\begin{tabular}{cccccc}
\hline $\begin{array}{c}\text { Kadar } \\
\text { Styrofoam }(\%)\end{array}$ & 0,00 & 1,00 & 2,00 & 3,00 & 4,00 \\
\hline VFB & 69,70 & 70,46 & 71,78 & 72,50 & 73,84 \\
\hline
\end{tabular}




\begin{tabular}{cccccc} 
& 70,23 & 71,16 & 71,78 & 72,33 & 73,44 \\
\cline { 2 - 6 } & 69,86 & 70,03 & 71,23 & 72,11 & 73,66 \\
\hline Rata-Rata & 69,93 & 70,55 & 71,60 & 72,31 & 73,65 \\
\hline
\end{tabular}

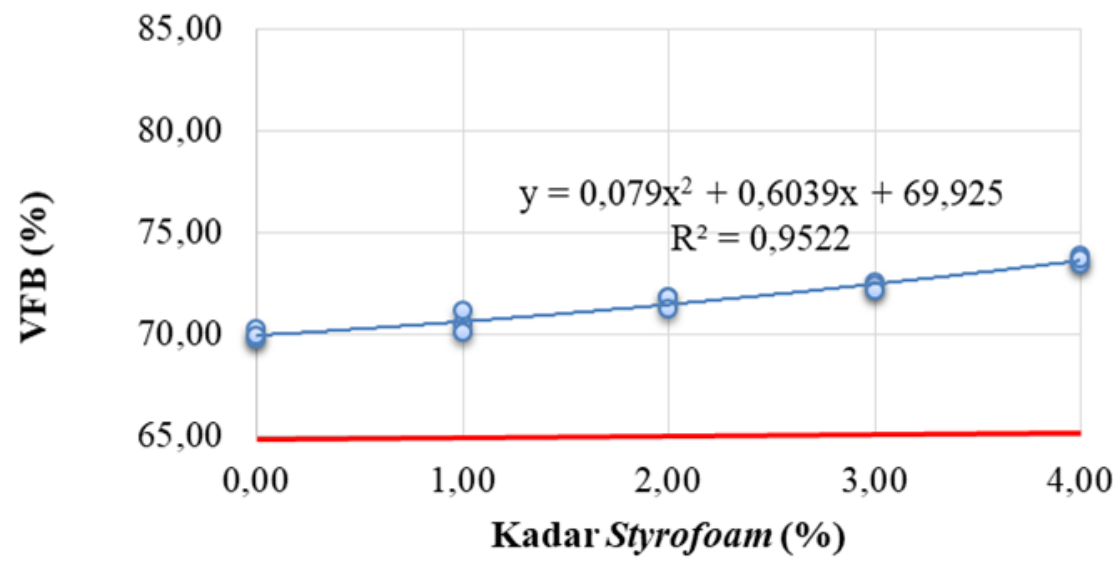

Gambar 5. Hubungan Kadar Styrofoam dengan VFB

Dengan Menggunakan kadar Styrofoam 0\%, 1\%, 2\%, 3\%, dan 4\% diperoleh nilai VFB untuk kadar Styrofoam 0\% sebesar 69,93\%, untuk kadar Styrofoam 1\% terjadi kenaikan sebesar 70,55\%, untuk kadar Styrofoam $2 \%$ terjadi kenaikan sebesar $71,60 \%$, untuk kadar Styrofoam 3\% terjadi kenaikan sebesar $72,31 \%$, dan untuk kadar Styrofoam $4 \%$ terjadi kenaikan sebesar 73,65\%. Semua nilai VFB dengan kadar Stytrofoam 0\%, 1\%, 2\%, 3\%, dan 4\% memenuhi Spesifikasi Umum Bina Marga Tahun 2018. Berdasarkan Gambar 5 bisa ditarik kesimpulan bahwa pemanfaatan Styrofoam di dalam kandungan campuran bisa mengakibatkan rongga yang berada dalam campuran tersebut menjadi terisi. Begitu juga kebalikannya bahwa Styrofoam dengan kadar yang besar dapat meningkatkan hasil VFB sebab semakin banyak penggunaan Styrofoam pada campuran tersebut mengakibatkan rongga-rongga yang gada menjadi terisi oleh Styrofoam.

Berdasarkan hasil pembahasan dari karakteristik campuran Laston Lapis Antara yaitu Stabilitas, VIM, Flow, VMA dan VFB didapatkan kadar Styrofoam maksimum yang dapat digunakan dan memenuhi spesifikasi Bina Marga 2018 sebesar 7,394\%. Penambahan Styrofoam sebesar 7,394\% memiliki nilai karakteristik campurannya yaitu Stabilitas sebesar 800,00 Kg, VIM sebesar 3,089\%, Flow sebesar 2,097 mm, VMA sebesar 14,707\% dan VFB sebesar 78,709\%.

\section{KESIMPULAN}

Hasil pengujian karakteristik Marshall Konvensional campuran Laston Lapis Antara dengan bahan tambah Styrofoam yaitu apabila kadar Styrofoam bertambah, maka nilai Stabilitas, dan VFB meningkat pada setiap kadar Styrofoamnya, sedangkan untuk nilai VIM, Flow dan VMA yang mengalami penurunan. Karakteristik Marshall Konvensional tersebut telah memenuhi spesifikasi Bina Marga 2018.

Pengaruh penambahan Styrofoam dapat meningkatkan kinerja campuran Laston Lapis Antara, dimana nilai stabilitas meningkat dan kelelehannya menurun.

\section{DAFTAR PUSTAKA}

[1] R. Krebs D. dan R. Walker D., Highway Materials,. Michigan: McGraw-Hill, Universitas Michigan, 1971. 
[2] R. Rachman, "The Effect of Immersion and Humidification Toward Performance of Hot Rolled Asphalt Mixture," Int. J. Appl. Eng. Res., vol. 15, no. 5, hlm. 503-509, 2020.

[3] G. Rusbintardjo, Aspal- Bahan Perkerasan Jalan, 1 ed. Semarang: UNISSULA Press, 2013.

[4] Transit New Zealand, Quality System for Road Construction, Road Maintenance and Structures Physical Contracts having a Normal QA Level. Wellington: Transit New Zealand, 2005.

[5] R. Rachman, "Karakteristik Campuran HRS - BASE Menggunakan Bubuk Dolomit Sebagai Filler," dalam Konfrensi Nasional Teknik Sipil Ke 13, Banda Aceh, Sep 2019, vol. 1, hlm. 420-430.

[6] A. Kusuma, "Material Subtitusi Filler," dalam Pemanfaatan Material Alternatif (Sebagai Bahan Penyusun Konstruksi), Makassar: CV. Tohar Media, 2021, hlm. 121-130.

[7] L. D. R. K. Salle, "Pemanfaatan Limbah," dalam Pemanfaatan Material Alternatif (Sebagai Bahan Penyusun Konstruksi), Makassar: CV. Tohar Media, 2021, hlm. 59-68.

[8] N. Sambo, R. Rachman, dan Alpius, "Pemanfaatan Limbah Styrofoam Sebagai Bahan Tambah Campuran AC-BC Yang Menggunakan Sungai Bittuang," Paulus Civ. Eng. J., vol. 3, no. 3, hlm. 330-340, 2021, doi: 10.52722/pcej.v3i3.283.

[9] N. Lolok, N. Ali, dan R. Rachman, "Pengaruh Styrofoam Sebagai Bahan Tambah Pada Campuran Laston Lapis Aus," Paulus Civ. Eng. J., vol. 3, no. 3, hlm. 397-405, 2021, doi: 10.52722/pcej.v3i3.291.

[10] R. Hermawan dan A. F. Ismaili, "Pemanfaatan Limbah Styrofoam Sebagai Bahan Additive pada Asphalt Concrete-Wearing Course (AC-WC) terhadap Karakteristik Marshall," Skripsi, Program Studi Teknik Sipil Fakultas Sains dan Teknologi Universitas Teknologi Yogyakarta, Yogyakarta, 2019.

[11] N. Risky, "Pengaruh Substitusi Styrofoam pada Campuran Asphalt Concrete - Binder Course (AC-BC) dengan Pengujian Marshall," Skripsi, Program Studi Teknik Sipil Fakultas Teknik Universitas Muhammadiyah Sumatera Utara, Medan, 2021.

[12] C. Kamba, "Agregat dari Material Lokal," dalam Pemanfaatan Material Alternatif (Sebagai Bahan Penyusun Konstruksi), Makassar: CV. Tohar Media, 2021, hlm. 35-46.

[13] A. Tangdiongan, "Pemanfaatan Batu Sungai Malili Kabupaten Luwu Timur Sebagai Agregat dalam Campuran Laston Lapis Antara," Skripsi, Program Studi Teknik Sipil Universitas Kristen Indonesia Paulus, Makassar, 2020. 